\title{
Introducción al Anuario Político de América Latina 2016
}

\author{
CRISTIAN PÉREZ MUÑOZ \\ Pontifica Universidad Católica de Chile
}

\section{CARSTEN-ANDREAS SCHULZ}

Pontifica Universidad Católica de Chile

En este número de Revista de Ciencia Política (RCP) se publica la novena edición del Anuario Político de América Latina. El Anuario nació en 2007 con el objetivo de convertirse en "testigo y documento de los hechos políticos que pautan cada año el acontecer regional, recuperando, además, las principales reflexiones teóricas que dichos hechos inspiran" (Altman y Luna 2007: 4). Inicialmente inspirado en el Political Data Yearbook publicado por el European Consortium for Political Research (ECPR), ${ }^{1}$ el Anuario de RCP busca fortalecer la investigación en ciencia política sobre América Latina proveyendo información confiable y de alta calidad. El Anuario no sólo recopila datos valiosos sobre variables políticas, económicas y sociales, sino también promueve una reflexión de coyuntura sobre lo sucedido en los países de la región en el lapso de un año.

El período de análisis de este número va del 1 de enero de 2016 al 31 de diciembre del mismo año. Como en cada edición del Anuario, los autores invitados a escribir sobre cada país reciben una pauta única de temas a considerar. ${ }^{2}$ Entre esos temas se encuentran:

(1) Cronología de los temas más importantes en la realidad nacional y su impacto político:
(a) coyuntura social
(b) coyuntura económica
(c) coyuntura subregional e internacional
(d) coyuntura política

\footnotetext{
Se puede acceder al Political Data Yearbook en el siguiente enlace: http:/ / www.politicaldatayearbook.com Los autores del anuario son invitados por los editores. No obstante, cada manuscrito es sometido a una evaluación anónima (doble ciega) por pares.
} 
(2) Cambios institucionales (y constitucionales) y cambios substanciales en políticas públicas

(3) Elecciones:

(a) resultados de elecciones nacionales y subnacionales (sean estas al ejecutivo, legislativo, mecanismos de democracia directa u otros)

(b) análisis de elecciones con especial énfasis en grupos desaventajados: mujer, étnicos, otros

(4) Poder ejecutivo:

(a) composición y rotación del gabinete

(b) análisis de funcionamiento del gabinete

(c) "estilos" presidenciales

(5) Poder legislativo:

(a) análisis de su composición partidaria

(b) análisis de su funcionamiento

6. Relación entre los poderes del estado (formal y de hecho).

7. Evaluación general sobre el funcionamiento y calidad de la democracia

Naturalmente, los autores contaron con la total libertad y discreción para enfatizar algunos de estos temas, tocar tangencialmente otros e incorporar tópicos no incluidos en la pauta. Con este esquema de trabajo se logran dos objetivos. Primero, generar una "crónica comparativa anual sobre los procesos políticos vividos por cada país" (Altman y Luna 2007: 4). Segundo, permitir que los autores den cuenta de acontecimientos y procesos políticos relevantes que escapan a la pauta pero no han sido previstos por el modelo propuesto.

Esta edición del anuario reúne un análisis de 15 países: Argentina, Bolivia, Brasil, Chile, Colombia, Costa Rica, Ecuador, El Salvador, Guatemala, México, Panamá, Paraguay, Perú, Uruguay y Venezuela. No obstante, una innovación para este número del anuario radica en la inclusión de dos artículos para el caso de Colombia, uno escrito por Juan Carlos Rodríguez Raga y otro por Sandra Botero. Mientras el primero de ellos sigue la pauta general del anuario, el segundo se focaliza en los pormenores del proceso de paz entre el gobierno colombiano y las Fuerzas Armadas Revolucionarias de Colombia (FARC), particularmente en el plebiscito por la paz de 2016. Confiamos que esta nueva edición del Anuario contribuya al avance de la investigación sobre la región, generando un registro y análisis de los procesos políticos más importantes del pasado 2016. 


\section{REFERENCIAS}

Altman, David y Juan Pablo Luna. 2007. “Desafección cívica, polarización ideológica y calidad de la democracia: una introducción al Anuario Político de América Latina." Revista Ciencia Política 27: 3-28. 
- 